\title{
Stage III Hypopharyngeal Carcinoma AJCC v8
}

National Cancer Institute

\section{Source}

National Cancer Institute. Stage III Hypopharyngeal Carcinoma A/CC v8. NCI Thesaurus.

Code C133007.

Stage III includes: (T3, N0, M0); (T1, N1, M0); (T2, N1, M0); (T3, N1, M0). T3: Tumor larger than $4 \mathrm{~cm}$ in greatest dimension or with fixation of hemilarynx or extension to esophagus. T1: T umor limited to one subsite of hypopharynx and/or $2 \mathrm{~cm}$ or smaller in greatest dimension. T2: Tumor invading more than one subsite of hypopharynx or an adjacent site, or measuring more than $2 \mathrm{~cm}$ but not more than $4 \mathrm{~cm}$ in greatest dimension without fixation of hemilarynx. N0: No regional lymph node metastasis. N1: Tumor with metastasis in a single ipsilateral lymph node, $3 \mathrm{~cm}$ or smaller in greatest dimension and ENE (-). M0: No distant metastasis. (AJCC 8th ed.) 